is authenticated by responsible officials or scientists. This avoids the 'contamination' of the database through deliberate or accidental introduction of spurious tiger images of dubious origin. A third objective is to ensure that photocapture dates and locations are entered accurately, to facilitate rigorous analyses of the data using spatially explicit capture-recapture models, as required by the new survey and estimation protocols already mandated by NTCA (http://projecttiger.nic.in/whtsnew/Protocol_Camera_trap. pdf).

The initiative to establish the UTID database was taken by Dr Rajesh Gopal, Director of Project Tiger, in October 2011 after a series of consultations with leading tiger researchers in India, including Dr Ullas Karanth of the Wildlife Conservation Society (WCS) and and Dr Y.V. Jhala of the Wildlife Institute of India (WII). A range of data collection and camera-trap sampling protocols, based on experience from the large-scale monitoring projects for tigers across India by WCS and WII, have been incorporated into the processes involved in generating field data. The pattern matching software Extract Compare, which speeds up individual identifications from stripe patterns on tigers (http://www.conservationresearch.co.uk), developed by Lex Hiby of Conservation Research, UK, with assistance from WCS scientists, will provide a robust and flexible platform. The database will be officially titled the National Repository of Camera Trap Photographs of Tigers (NRCTPT). It is anticipated that $>1,400$ individual tigers camera trapped by WCS and WII surveys conducted after 1 January 2006 will form the initial core of the database. Subsequently, it is anticipated that the database will expand through active participation of other researchers conducting camera trap surveys and with authenticated tiger images obtained from other sources such as police seizures of skins, poached tigers, conflict related removals, and tourist or other incidental photographs of tigers. Currently, the WCS database of tiger IDs in Karnataka has over 4,000 images of 600 individual tigers from multiple sources, used for rapid sharing of information with State Forest Department and NTCA in real time, as tiger conservation issues arise. Begun in 1986 by Dr Karanth and now covering an area of $4,000 \mathrm{~km}^{2}$ of prime tiger habitat in Karnataka, this WCS project pioneered development of camera-trap surveys of tigers in 1991. In the long term the NRCTPT project is expected to facilitate not just the accurate monitoring of key surviving source populations of India's national animal but also to help effective conservation decision making in case of humantiger conflict incidents and to address the burgeoning problem of poaching of tigers across the country.

Narendra Patil, SAmba N. Kumar and PRERNA Singh Bindra Wildife Conservation Society-India Program, 1669,

31st Cross, 16th Main, Banashankari 2nd Stage, Bengalooru 560 070, India. E-mail narendra.patil.cws@gmail.com

\section{Regional dialogue to counter escalating large-scale transboundary poaching in Central Africa}

Large-scale poaching in Central Africa, targeting elephants in particular, has reached dramatic levels. In early 2012 Cameroon was the scene of the latest slaughter, with $>300$ elephants lost in Bouba Ndjida National Park, involving poachers from Sudan and elsewhere. This is just the latest example of an escalating phenomenon, resulting from the spillover of armed conflicts, collapsing protected areas and lawlessness. Over the last 3 decades the northern Central African Republic has lost over 95\% of its 35,000 elephants, and other wildlife. Since 2005 Zakouma National Park in Chad has lost $85 \%$ of its 4,000 elephants, and continues to lose them.

Widespread international attention and high-level political support has caused the Cameroonian Minister of Forestry and Wildlife to develop an emergency action plan to secure the protected areas of its northern border. Contributing to the regional component of this plan, the Central African Forest Commission (COMIFAC), with support from the Réseau des Aires Protégées d'Afrique Centrale and the German Technical Development Cooperation, organized a meeting in June 2012 of ministers of the Central African Republic, Chad and Cameroon, to initiate a dialogue on reinforced transboundary anti-poaching control. In a preparatory meeting the directors of wildlife, park wardens and other delegation members exchanged experiences on the Bouba Ndjida massacre. The Central African Republic delegation presented information on the passage of 150 and 80 men through Sangba, in the north, 4-6 weeks after they left Cameroon heavily loaded with tusks and after having killed seven elephants. In November 2012 we received information from the northern Central African Republic of sightings of presumed poachers, returned from Sudan earlier than expected. A health worker, who treated one of them, reported he was from the group that poached the Bouba Ndjida elephants. Two columns of heavily armed men were subsequently observed heading towards the Chadian border. One elephant was reported killed. The most recent report at the time of writing (February 2013) is that the group had reportedly split up, some observed again around Bouba Ndjida National Park whereas others had moved into the forested south-west of the Central African Republic.

The three countries signed a declaration on the reinforcement of combating cross-boundary poaching, highlighting the interest in wildlife survival, as well as of security of personnel in border areas. In the declaration's implementation plan each of the three countries commits itself to submitting the necessary budgets for anti-poaching and improving the status of protected area personnel. In addition, a road map was signed to operationalize the cooperation agreement of the Bouba Ndjida-Sena 
Oura transboundary complex between Cameroon and Chad. Ministers asked to include the Central African Republic in the accord, subject to follow-up tripartite meetings in Ndjamena in September and November 2012 in which an agreement on anti-poaching transboundary collaboration was prepared. In June 2012 the ministers in charge of wildlife of the COMIFAC member states also adopted the Central African Wildlife Trade Law Enforcement Action Plan (CAWTLEAP, 2012-2017). News as at February 2013 is that, recognizing the increasingly military character of effective anti-poaching, the dialogue amongst the three ministers in charge of wildlife is to be widened to include their colleagues in charge of defence.

Important first steps have been taken with this longawaited tri-national dialogue and signing of CAWTLEAP but more is needed. The dramatic increase in elephant poaching has been triggered by the rapidly increasing demand for ivory in China, Thailand and other East Asian countries. Regional and intercontinental dialogue, including ivory consumer and transit countries, was called for by a platform meeting organized jointly by the US Embassy and the Governments of Gabon and Central African Republic in Libreville in April 2012. The greatest challenge now is to translate these dialogues into concrete collaboration. This may be boosted by treating the illegal international wildlife trade as a crime that mobilizes action beyond ministries in charge of wildlife protection. As called for by CAWTLEAP, national units to combat wildlife crime are being established, comprising law enforcement agencies (Defence, Justice, Customs, Police, Wildlife, Interior and Exterior) and assisted by technical partners such as INTERPOL, conservation organizations and diplomatic missions. These units are being tasked to bundle resources and intelligence systems to track, arrest and prosecute wildlife criminals to the full extent of the law.

This attention to large-scale transboundary poaching should not, however, divert attention from increasingly commercial small-scale poaching operations, with implication of powerful elites, for which collaboration with local communities should, whenever possible, be reinforced. Only reacting to these different types of poaching will ensure that elephants and other wildlife do not follow the same fate as the western black rhino, extinct a decade ago.

PAUL SCHOLTE GIZ-COMIFAC support programme, Yaounde, Cameroon.E-mail paul.scholte@giz.de

Chouatbou NChoutpouen Executive Secretariat COMIFAC, Yaounde, Cameroon

BAS HUIJBREGTS WWF-CARPO, Yaounde, Cameroon

\section{A new market-based tool for conservation: improving aquaculture through ASC certification}

Almost half of all seafood comes from aquaculture farms and by 2018 more seafood will be farmed than caught from the wild. Reconciling food security with the protection of aquatic and marine ecosystems is a major conservation challenge. Solutions need to address both the demand of an increasing global population as well as the market forces that supply that demand.

In August 2012 the first seafood bearing the Aquaculture Stewardship Council's (ASC) 'responsibly farmed' logo entered the market place. The ASC logo is complimentary to the Marine Stewardship Council's label for sustainablycaught wild fish. The ASC represents the latest major certification initiated by WWF's Markets Transformation Initiative, which uses market forces for conservation benefits across commodities, including forests (Forest Stewardship Council), soya (the Roundtable for Responsible Soy), sugar (Bonsucro), cotton (Better Cotton), palm oil (Roundtable on Sustainable Palm Oil) and freshwater (Alliance for Water Stewardship).

The ASC logo encompasses a series of standards for major farmed species and was developed through an international, multi-stakeholder process involving c. 2,000 experts globally over 8 years. As with other environmental certification schemes of this magnitude, a commitment to ongoing development and improvement of the standards is critical. The ASC standards contain performance indicators (metrics) designed to improve the viability of threatened and protected species, essential habitat, freshwater quantity and quality, carbon and greenhouse gas emissions, and the management of wild fisheries and terrestrial crops used in feed. These measures, as well as social considerations, are formally assessed by teams of independent experts, led by accredited auditors with the technical background to evaluate impacts. Producers are required by the team to improve practices to meet conditions for certification. Auditor manuals contain specific instructions and methods with actionable and measurable steps for producers to implement best practices. Standards also have meaningful data-reporting requirements that will increase global knowledge of aquaculture, and some standards ask producers to initiate area-based management plans to address cumulative impacts. Increased market access, profits and indirect benefits (e.g. public recognition, funding, increased harmony with surrounding communities) are all powerful incentives for those interested in demonstrating commitment to responsible production.

At present, ASC-labelled Tilapia and Pangasius are available to consumers, with further categories that include salmon, bivalves, abalone, freshwater trout, shrimp, Seriola and cobia to emerge over the next year. In the past 3 months 